\title{
Double Layer Material Designed to Reduce Electromagnetic Radiation with Carbon Black, Silicon Carbide and Manganese Zinc Ferrite
}

\author{
Ariane Aparecida Teixeira de Souza ${ }^{1, *}$ (D), Nila Cecília de Faria Lopes Medeiros ${ }^{1,2}$ (D), Leonardo lusuti de \\ Medeiros $^{1,2}(\mathbb{D})$, Gisele Aparecida Amaral-Labat ${ }^{1}(\mathbb{D})$, Matheus Carvalho Bispo ${ }^{3}(\mathbb{D}$, Guilherme Frederico \\ Bernardo Lenz e Silva ${ }^{4}$, Alan Fernando Ney Boss ${ }^{4}$ (D), Mauricio Ribeiro Baldan ${ }^{1}$ (D)
}

\begin{abstract}
1.Instituto Nacional de Pesquisas Espaciais - Coordenação de Pesquisa Aplicada e Desenvolvimento Tecnológico - Grupo de Materiais Avançados e Pesquisas Aeroespaciais - São José dos Campos/SP - Brazil. 2.Universidade Estadual De Santa Cruz Departamento de Ciências Exatas e Tecnológicas - Curso de Engenharia Mecânica - Ilhéus/BA - Brazil. 3.Instituto de Estudos Avançados - Departamento de Ciência e Tecnologia Aeroespacial - Divisão de Física Aplicada - São José dos Campos/SP - Brazil. 4.Universidade de São Paulo - Escola Politécnica - Departamento de Engenharia Metalúrgica e de Materiais - São Paulo/SP, Brazil.
\end{abstract}

*Corresponding author: ariane_apts@hotmail.com

\begin{abstract}
Radar absorbing materials (RAMs) are composites made with a polymeric matrix and an electromagnetic absorbing filler, such as carbon black (CB), silicon carbide ( $\mathrm{SiC}$ ) or manganese zinc ferrite $(\mathrm{MnZn})$. To enhance their performances to attenuate an incident wave through reflection loss (RL), RAMs can be produced in multilayer structures. Usually, the RL analysis is done theoretically and experimentally validated with free space analysis. Here, it was demonstrated that multilayer structure can be designed and easily validated using rectangular waveguide, using a simpler setup and small samples. Three composites were produced using $2 \mathrm{wt} \%$ of $\mathrm{CB}(\mathrm{CB} 2), 40 \mathrm{wt} \%$ of $\mathrm{SiC}$ ( $\mathrm{SiC} 40$ ) and $60 \mathrm{wt} \%$ of MnZn (MnZn60). They were characterized over the $\mathrm{K}_{u}$-band and used to validate the multilayer structures, that were prepared by simply stacking each material inside the waveguide sample holder. One of the best results was obtained with structure $\mathrm{SiC} 40+\mathrm{CB} 2$ with $5.85 \mathrm{~mm}$ thickness, that presented a calculated RL of $-21 \mathrm{~dB}$ at $17.8 \mathrm{GHz}$ and a measured RL of $-36 \mathrm{~dB}$ at the same frequency. In conclusion, using rectangular waveguide has been proven to be an easy, cheap, precise and fast approach to validate multilayer structures designs.
\end{abstract}

Keywords: Radar Absorbing Material, Multilayer Structure, Reflection Loss, Permittivity, Electromagnetic Pollution.

\section{INTRODUCTION}

Radar absorbing materials (RAMs) are materials designed to reduce the electromagnetic reflection (or transmission) over a frequency range. They can be applied as electromagnetic shield in several areas, such as military, aeronautic, aerospace and telecommunications (Hong et al. 2015). Several types of RAMs and absorbing structures have been developed over the decades, such as: single layer RAMs (Liu et al. 2014a); multilayer RAMs (Datashvili et al. 2006); frequency selective surface (Chung 2004; Vergara et al. 2019); and others (Ahmad et al. 2019). These materials can be used to protect electronics from the electromagnetic pollution created by thousands of

Received: Jun. 25, 2020 | Accepted: Nov. 17, 2020

Peer Review History: Double-blind Peer Review.

Section Editor: Selim Gürgen

This is an open access article distributed under the terms of the Creative Commons license. 
electronic devices, as well as prevent electronics to enhance this pollution. This strategy can contribute to reduce electromagnetic interferences between electronic and even carcinogens issues on humans (Calabrò 2018; Fernández-Chimeno and Silva 2010).

Radar absorbing materials are usually applied to stealth technology in military areas (Micheli et al. 2014; Jayalakshmi et al. 2019), but they can also be used as antenna on microstrip devices (Khandelwal et al. 2014). Because of that, RAMs have been extensively studied in the $\mathrm{X}$-band frequency range $(8.2-12.4 \mathrm{GHz})$, that is the operational frequency of several radars and communication systems. Usually, RAMs are composites made with a polymeric matrix and one (or more) dielectric and/or magnetic losses fillers, such as: NiZn ferrite (Yadoji et al. 2003); graphene oxide (Wen et al. 2014; Balci et al. 2015); carbon fiber (Cao et al. 2010); manganese zinc ferrite (MnZn) (Gama and Rezende 2013); carbon black (CB) (Barba et al. 2006; Jani et al. 2017); and silicon carbide (SiC) (Liu et al. 2011; Yassuda and Castro 2014).

Strategies such as multilayer structures are required to improve the reflection loss (RL) of materials with low-absorption at higher frequencies, such as the $\mathrm{K}_{u}$-band (12.4-18.0 GHz) (Park et al. 2011). However, most researches of multilayer structures in the $\mathrm{K}_{u}$-band are made with RL equations because the materials are characterized from 2 to $18 \mathrm{GHz}$ using coaxial waveguide (Feng et al. 2007). Research with experimental RL data is performed with free space analysis (Zang et al. 2015), but this method requires large samples and a complex and expensive setup with an anechoic chamber. Some researches present the RL measurement of smaller samples using rectangular waveguides, but they are either measured as single layer RAMs (Liu et al. 2014a; Oliveira et al. 2018) or the RAM is characterized and further calculated as a double layer structure (Nagasree et al. 2020). Here, three RAMs were fabricated using $\mathrm{CB}, \mathrm{SiC}$ and $\mathrm{MnZn}$, characterized them in the $\mathrm{K}_{\mathrm{u}}$ frequency range, calculated the RL of multilayer structures, and validated the RL through measurements using rectangular waveguide.

\section{METHODOLOGY}

\section{Material}

All samples were made using an accessible, inexpensive, easy-handle, nontoxic commercial silicone rubber BX-8001 (Redelease Ltda) as polymeric matrix. Redelease rubber catalyst (Redelease Ltda) was employed for fast hardening. The dielectric and/or magnetic fillers used were CB XC72R (Cabot Corp.), SiC with particle size of $44 \mu \mathrm{m}$, and MnZn ferrite with $400 \mathrm{k} \Omega \mathrm{m}$ resistivity and $4.6 \mathrm{~g} / \mathrm{cm}^{3}$ density. Silicon carbide and MnZn ferrite were kindly provided by Saint-Gobain S.A. and IMAG Indústria e Comércio de Componentes Eletrônicos Ltda., respectively.

All composites were prepared based on a standard protocol developed in the laboratory that ensures high homogeneity for small samples. The protocol consists of manually mixing filler and matrix for $5 \mathrm{~min}$, add $5 \mathrm{wt} \%$ of catalyst, mix for $30 \mathrm{~s}$ more, and pour it in an $3 \mathrm{D}$ printed mold designed with the $\mathrm{K}_{u}$-band dimensions $(15.7 \times 7.9 \mathrm{~mm})$. Samples were left for hardening during $24 \mathrm{~h}$ at room temperature. The mass proportions used to prepare each composite are presented in Table 1. Additionally, it is presented the thickness of each sample used in the multilayer structure, that was measured with a digital caliper. The multilayer structure was prepared by stacking the composites over each other. Figure 1 presents a picture of each composite, as well as the position of a multilayer structure.

Table 1. Samples composition and nomenclature.

\begin{tabular}{|c|c|c|c|}
\hline Name & Matrix & Filler & Thickness [mm] \\
\hline \multirow{2}{*}{ СВ2 } & \multirow{2}{*}{98 wt\% of silicone rubber } & \multirow{2}{*}{$2 \mathrm{wt} \%$ of $\mathrm{CB}$} & 3.00 \\
\hline & & & 4.00 \\
\hline \multirow{3}{*}{ SiC40 } & \multirow{3}{*}{$60 w t \%$ of silicone rubber } & \multirow{3}{*}{$40 \mathrm{wt} \%$ of $\mathrm{SiC}$} & 2.35 \\
\hline & & & 2.85 \\
\hline & & & 3.50 \\
\hline \multirow{2}{*}{ MnZn60 } & \multirow{2}{*}{$40 w t \%$ of silicone rubber } & \multirow{2}{*}{$60 \mathrm{wt} \%$ of $\mathrm{MnZn}$} & 2.20 \\
\hline & & & 2.90 \\
\hline
\end{tabular}




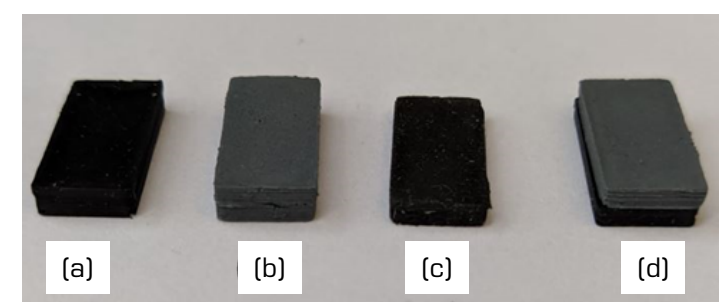

Figure 1. Samples (a) CB2, (b) SiC40, (c) MnZn60 and (d) the multilayer structure SiC+CB2, where SiC is above CB2.

\section{METHODS}

The electromagnetic characterizations were made with a vector network analyzer (VNA), Keysight N5232A, coupled with a rectangular waveguide $\mathrm{P} 11644 \mathrm{~A}$ that works between 12.4 - $18 \mathrm{GHz}\left(\mathrm{K}_{u}\right.$-band).

The RL of the multilayer systems were calculated using the measured complex permittivity $\left(\varepsilon=\varepsilon^{\prime}-\mathrm{j} \varepsilon^{\prime \prime}\right)$ and permeability $\left(\mu=\mu^{\prime}-\mathrm{j} \mu\right.$ ") over the entire frequency range. These calculations allow the exploration of several combinations of multilayer structures to improve the reflection loss of the final structure. The equations to calculate the RL of multilayer structures are presented in Eqs. 1-4 (Liu et al. 2014b):

$$
\begin{gathered}
R L=-20 \log _{10}\left[\frac{Z_{\text {in }}-Z_{0}}{Z_{\text {in }}+Z_{0}}\right] \\
Z_{i n}=Z_{1} \frac{Z_{\text {in } 1}+Z_{1} \tanh \left[j\left(2 \pi f \frac{d_{1}}{c}\right) \sqrt{\mu_{1} \varepsilon_{1}}\right]}{Z_{1}+Z_{i n_{1}} \tanh \left[j\left(2 \pi f \frac{d_{1}}{c}\right) \sqrt{\mu_{1} \varepsilon_{1}}\right]} \\
Z_{i n_{1}}=Z_{2} \tanh \left[j\left(2 \pi f \frac{d_{2}}{c}\right) \sqrt{\mu_{2} \varepsilon_{2}}\right] \\
Z_{n}=\sqrt{\frac{\mu_{n}}{\varepsilon_{n}}}, \mathrm{n}=1,2
\end{gathered}
$$

Here, $Z_{\text {in }}$ is the input impedance between free space and material interface; $Z_{\text {in } 1}$ is the impedance between layer 1 and layer $2 ; Z_{0}$ is the characteristic impedance of free space $Z_{n}$ is the characteristic impedance of the $n$-layer; $\varepsilon_{n}$ is the complex permittivity of the $n$-layer; $\mu_{n}$ is the complex permeability of the $n$-layer $d_{1}$ is the thickness of the first layer and the $d_{2}$ is the thickness of the second layer; $c$ the speed of light in the free space and; $f$ is the frequency of the electromagnetic wave in the free space. These parameters are illustrated in Fig. 2.

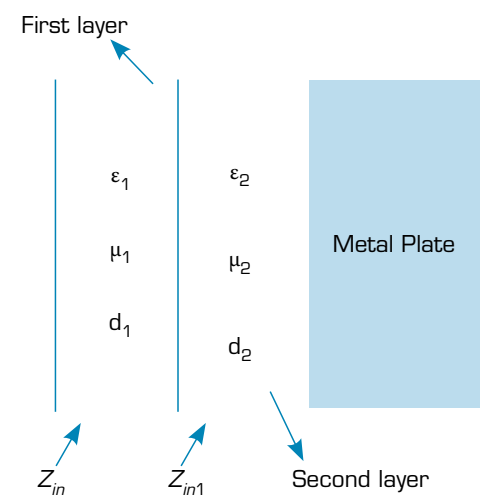

Figure 2. Multilayer system representation with all properties required for double layer RL calculation. 


\section{RESULTS AND DISCUSSION}

Morphological characteristics such as grain size and geometry were evaluated through scanning electron microscope (SEM) images of $\mathrm{SiC}, \mathrm{CB}$ and $\mathrm{MnZn}$ ferrite (Fig. 3). Silicon carbide presented particles smaller than $44 \mu \mathrm{m}$, and a prismatic geometry that is typical from hard and fragile ceramic materials. Carbon black presented a characteristic cluster of nanometric spheres, and $\mathrm{MnZn}$ ferrite showed faceted particles ranging from 10 to $50 \mu \mathrm{m}$.

(a)

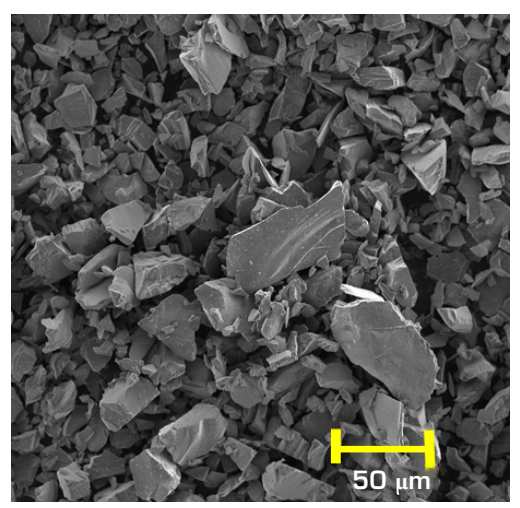

(b)

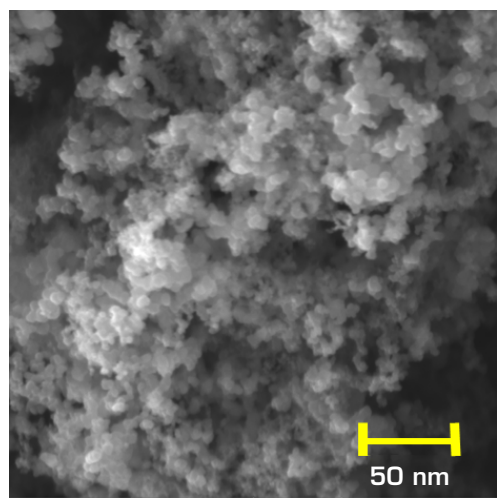

(c)

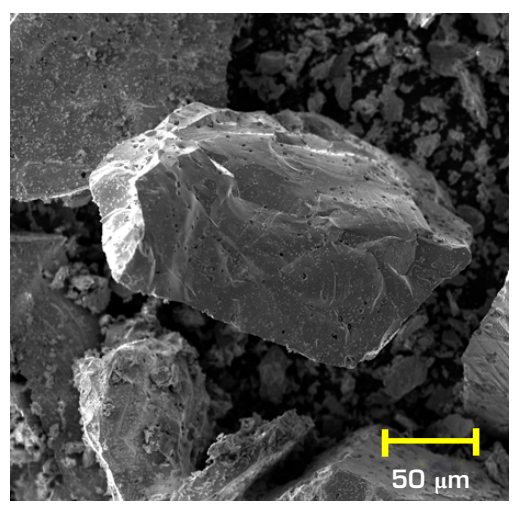

Figure 3. SEM images of (a) SiC (b) CB (c) MnZn fillers.

The planes and positions of each material were identified through X-ray diffraction (XRD) analyses (Fig. 4). The power diffraction file (PDF) cards used were: SiC (01-075-1541); CB (00-041-1487); and MnZn ferrite (01-089-7555). Silicon carbide and $\mathrm{MnZn}$ ferrite showed well-defined peaks that confirm their crystalline structure, while CB diffractogram presents the characteristic peaks of amorphous carbon, corresponding to (002) and (101) planes. The main phase of SiC, MnZn and CB was identified as moissanite- $6 \mathrm{H}(\mathrm{SiC})$, franklinite $\left(\mathrm{Fe}_{2} \mathrm{O}_{4} \mathrm{Zn}\right)$ and hexagonal graphite $-2 \mathrm{H}(\mathrm{C})$.
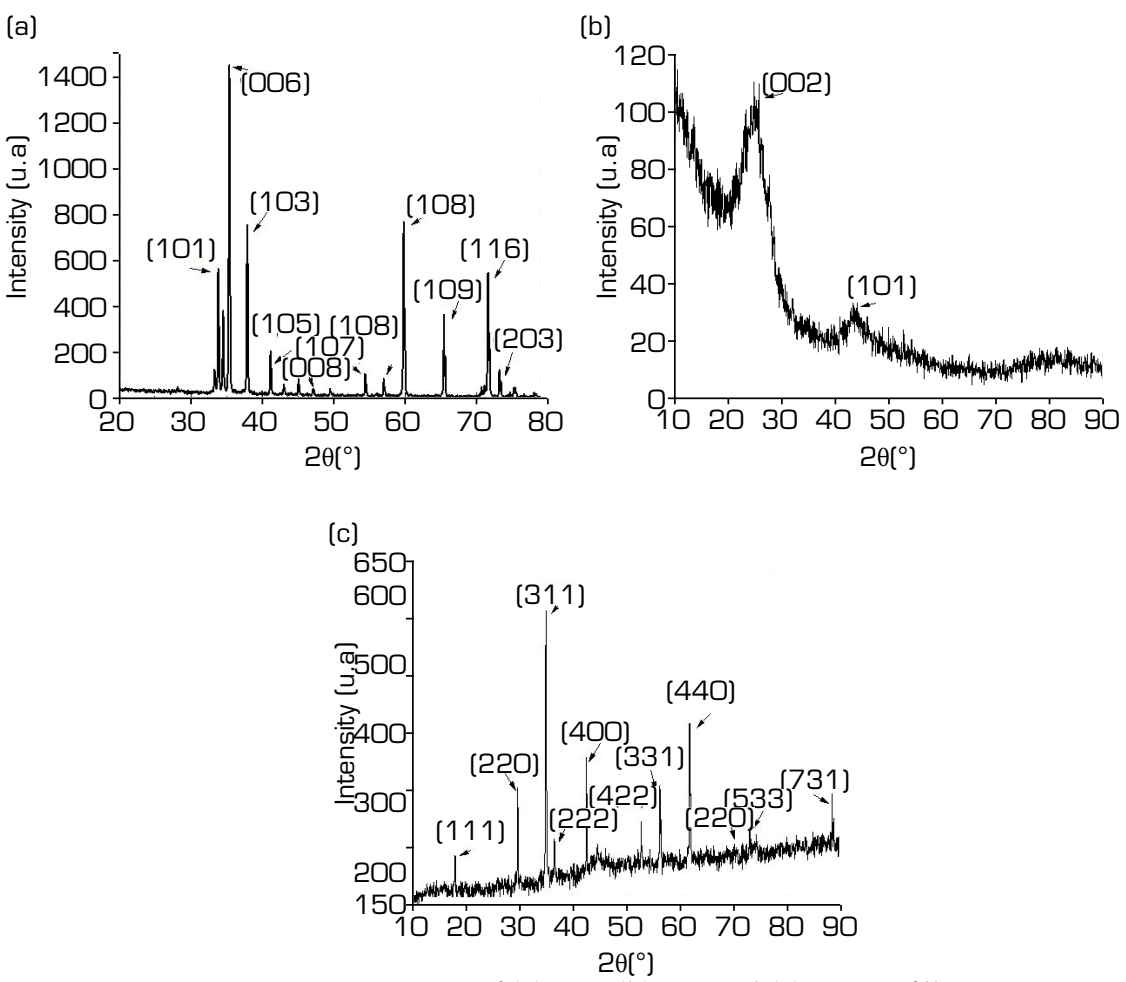

Figure 4. XRD patterns of (a) $\mathrm{SiC}$, (b) $\mathrm{CB}$ and (c) MnZn fillers. 
The complex permittivity and permeability are the dielectric and the magnetic properties of materials, respectively. The real part of permittivity and permeability $\left(\varepsilon^{\prime}\right.$ and $\left.\mu^{\prime}\right)$ are related to the capacitive phenomena, while the imaginary parts $\left(\varepsilon^{\prime \prime}\right.$ and $\left.\mu^{\prime \prime}\right)$ are related to the dissipative phenomena (Nagasree et al. 2020). The electromagnetic properties of all samples are almost constant over the entire $\mathrm{K}_{u}$-band, as can be seen in Fig. 5. This can be verified through the averaged values of the electromagnetic properties over the entire frequency range. The average complex permittivity for sample MnZn60 throughout the $\mathrm{K}_{u}-\mathrm{band}$ is $\varepsilon^{\prime}=9.88 \pm 0.12$ and $\varepsilon^{\prime \prime}=1.20 \pm 0.31$, while the averaged complex permeability is $\mu^{\prime}=0.53 \pm 0.01$ and $\mu^{\prime \prime}=0.01 \pm 0.03$. Sample SiC40 has an average complex permittivity of $\varepsilon^{\prime}=6.82 \pm 0.10$ and $\varepsilon^{\prime \prime}=1.06 \pm 0.08$, and an averaged complex permeability of $\mu^{\prime}=1.02 \pm 0.01$ and $\mu^{\prime \prime}=0.02 \pm 0.01$. Carbon black (CB2) sample presents an average complex permittivity of $\varepsilon^{\prime}=3.09 \pm 0.01$ and $\varepsilon^{\prime \prime}=0.14 \pm 0.01$, and an averaged complex permeability of $\mu^{\prime}=0.96 \pm 0.01$ and $\mu^{\prime \prime}=0.01 \pm 0.01$. It is important to mention that these averaged values are just to demonstrate that the electromagnetic properties remain constant over the entire frequency range, but the RL are calculated using the permittivity and permeability values that are presented in the graphs.
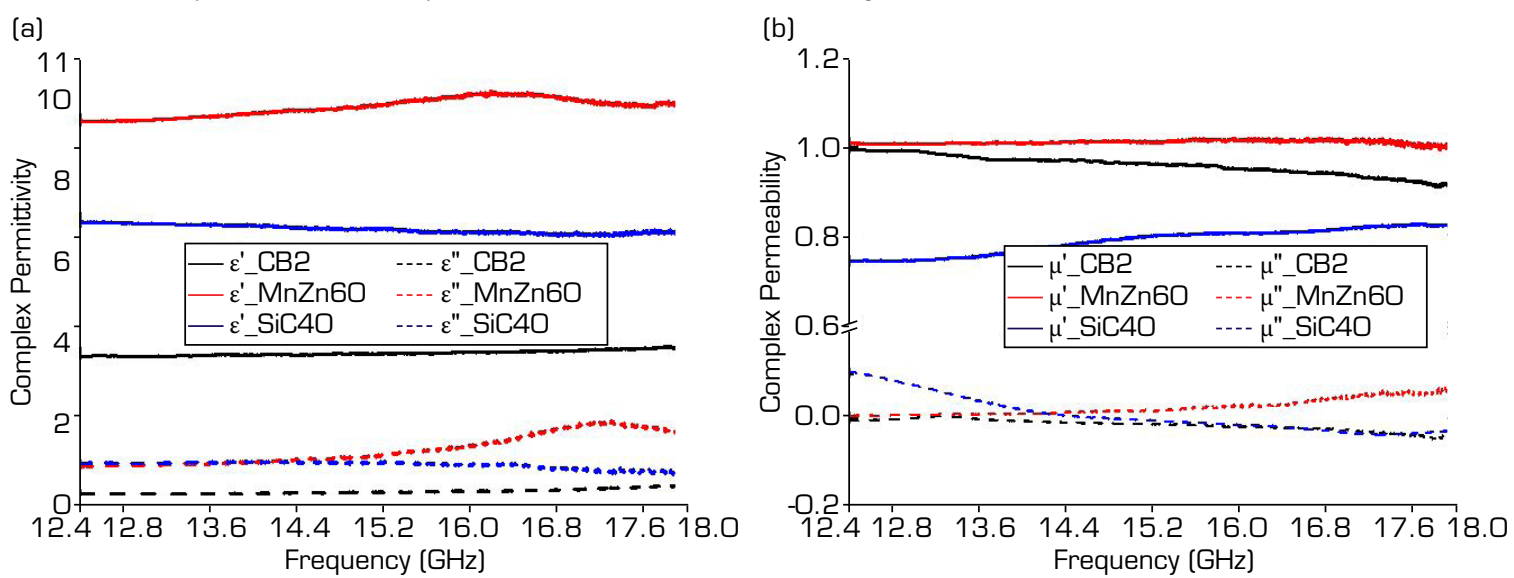

Figure 5. (a) Complex permittivity and (b) complex permeability of samples CB2, SiC40 and MnZn60.

The dielectric and magnetic tangent losses for all samples are presented in Fig. 6 , where the dielectric losses $\left(\tan \delta_{\varepsilon}=\varepsilon^{\prime \prime} / \varepsilon^{\prime}\right)$ play a more important role dissipating the electromagnetic wave than the magnetic losses $\left(\tan \delta_{\mu}=\mu^{\prime \prime} / \mu^{\prime}\right)$.

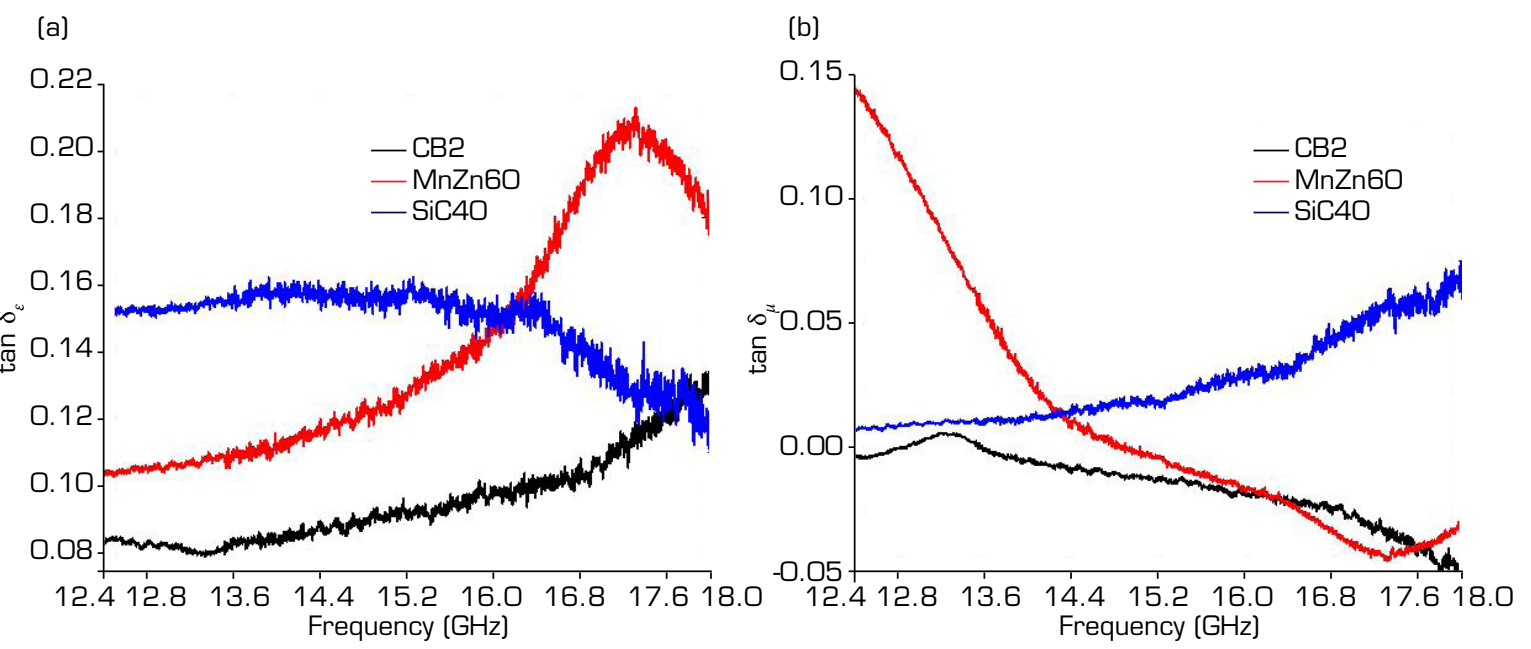

Figure 6. The (a) dielectric and (b) magnetic tangent losses for all samples.

The attenuation constant ( $\alpha$ ) was calculated through Eq. 5 (He et al. 2019): 


$$
\alpha=\frac{\sqrt{2} \pi f}{c} \times \sqrt{\left(\mu^{\prime \prime} \varepsilon^{\prime \prime}-\mu^{\prime} \varepsilon^{\prime}\right)+\sqrt{\left(\mu^{\prime \prime} \varepsilon^{\prime \prime}-\mu^{\prime} \varepsilon^{\prime}\right)^{2}+\left(\mu^{\prime \prime} \varepsilon^{\prime}+\mu^{\prime} \varepsilon^{\prime \prime}\right)^{2}}}
$$

Figure 7 shows that MnZn60 attenuates the incident wave better than $\mathrm{SiC} 40$ up to $13.6 \mathrm{GHz}$, but SiC40 can attenuate it better at higher frequencies. The oscillation in the MnZn60 attenuation constant is related to the variations in the complex permittivity. Although those oscillations are small, they became larger in the attenuation constant because they are frequency dependent, as can be seen in Eq. 5. The SiC40 and CB2 samples present linear values that increase with increasing frequency, as expected for constant values of permittivity and permeability.

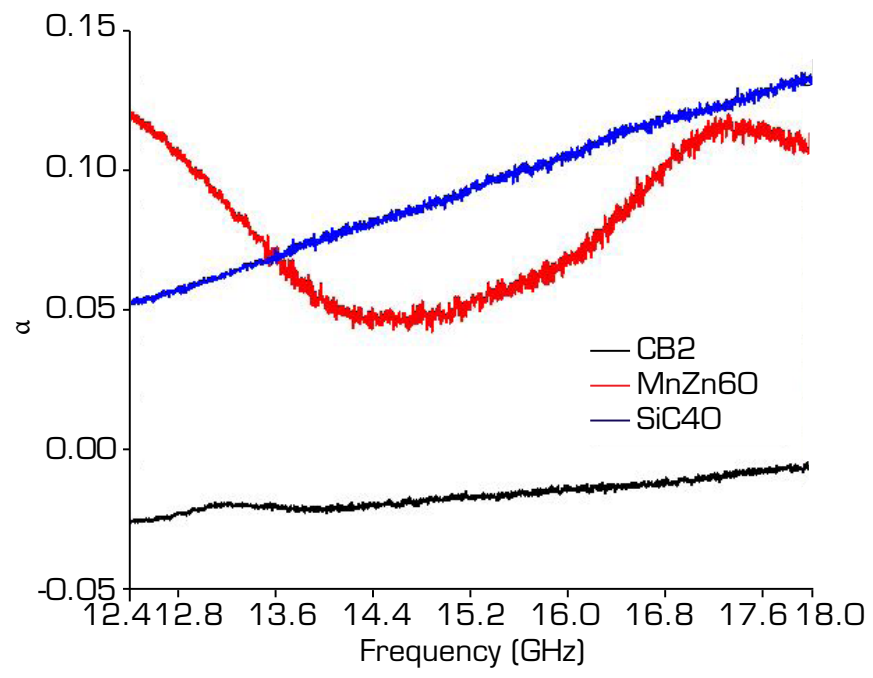

Figure 7. Attenuation constant of all samples.

The experimental RL of each individual material is presented in Fig. 8. The CB2 sample alone does not present a considerable reflection loss, as seen in Fig. 8a. This behavior is probably related to the proportion of CB in the silicone rubber, that was not enough to achieve an electric percolation once it accepts 3-4 wt\% of CB accordingly to empirical analysis. The reflection loss for samples MnZn60 and SiC40 present better absorption properties, and the results are shown in Fig. 8b and 8c, respectively. The best result for MnZn60 composite was the one with $4.27 \mathrm{~mm}$ thickness, reaching $-16.0 \mathrm{~dB}$ at $14.1 \mathrm{GHz}$. This sample has an absorption bandwidth (BW) of $0.6 \mathrm{GHz}$, i.e., the RL is below $-10 \mathrm{~dB}$ over $600 \mathrm{MHz}$. The SiC40 sample with $2.00 \mathrm{~mm}$ thickness presented a $\mathrm{RL}$ of $-14.6 \mathrm{~dB}$ at $14.7 \mathrm{GHz}$, with an absorption bandwidth of $2.5 \mathrm{GHz}$. Other SiC40 samples with different thicknesses also had a RL below $10 \mathrm{~dB}$, such as the samples with $1.60 \mathrm{~mm}(\mathrm{RL}=-11.5 \mathrm{~dB}$ at $16.1 \mathrm{GHz}$ and $\mathrm{BW}=0.9 \mathrm{GHz}), 5.02 \mathrm{~mm}(\mathrm{RL}=-15.0 \mathrm{~dB}$ at $17.3 \mathrm{GHz}$ and $\mathrm{BW}=2.4 \mathrm{GHz})$ and $5.97 \mathrm{~mm}(\mathrm{RL}=-14.1 \mathrm{~dB}$ at $14.8 \mathrm{GHz}$ and $\mathrm{BW}=1.2 \mathrm{GHz})$. Since RL is thickness dependent, a shift towards lower frequencies is observed in Fig. $8 \mathrm{c}$ as samples get thicker.

The best values of multilayers structures were found using Eqs. 1 to 4 . The calculations were made in an Excel spreadsheet and respected the maximum total thickness of $6.5 \mathrm{~mm}$, since it is the thickness of the rectangular waveguide sample holder. The first structure investigated was the double layer structure with MnZn60 composite as layer 1 and CB2 composite as layer 2. The experimental and calculated RL for this multilayer are presented in Fig. 9. Two structures with different total thicknesses presented good RL: one with $5.90 \mathrm{~mm}$ and another $6.20 \mathrm{~mm}$. The calculated RL for the structure with $5.90 \mathrm{~mm}$ thickness $(\mathrm{MnZn} 602.90 \mathrm{~mm}+\mathrm{CB} 2$ $3.00 \mathrm{~mm}$ ) was $-21.2 \mathrm{~dB}$ at $15.9 \mathrm{GHz}$, while the measured $\mathrm{RL}$ was $-30.2 \mathrm{~dB}$ at $16.0 \mathrm{GHz}$. The frequency difference between the experimental and calculated peaks is $0.1 \mathrm{GHz}$. The structure with $6.20 \mathrm{~mm}$ thickness $(\mathrm{MnZn} 602.20 \mathrm{~mm}+\mathrm{CB} 24.00 \mathrm{~mm}) \mathrm{had}$ a calculated RL of $-40.2 \mathrm{~dB}$ at $17.1 \mathrm{GHz}$, while the measured RL was $-14.5 \mathrm{~dB}$ at $16.9 \mathrm{GHz}$. The frequency difference between them is $0.2 \mathrm{GHz}$. These structures also presented a good experimental absorption bandwidth: $1.0 \mathrm{GHz}$ for structure MnZn60 $2.90 \mathrm{~mm}+\mathrm{CB} 23.00 \mathrm{~mm}$ and $1.2 \mathrm{GHz}$ for structure MnZn60 2.20 mm + CB2 $4.00 \mathrm{~mm}$. These structures presented a better RL than both individual composites samples, and a shift towards lower frequencies with a thinner structure. 
The second set of double layer structures were evaluated considering SiC composite as layer 1 and CB2 composite as layer 2 (Fig. 10). The structure with a total thickness of $6.50 \mathrm{~mm}$ (SiC40 $3.50 \mathrm{~mm}+\mathrm{CB} 23.00 \mathrm{~mm})$ theoretically attenuates $-19.2 \mathrm{~dB}$ at $15.9 \mathrm{GHz}$. However, the measured RL was $-33.6 \mathrm{~dB}$ at $16.0 \mathrm{GHz}$, which is a significant improvement of the RL with a slight frequency difference of $0.1 \mathrm{GHz}$. The experimental absorption bandwidth of this structure was $1.7 \mathrm{GHz}$. The sample with $6.35 \mathrm{~mm}$ (SiC40 $2.35 \mathrm{~mm}+\mathrm{CB} 24.00 \mathrm{~mm}$ ) had a calculated RL close to $-20.6 \mathrm{~dB}$ at $16.9 \mathrm{GHz}$, while the measured RL was $-24.5 \mathrm{~dB}$ at $16.9 \mathrm{GHz}$. The frequency difference between experimental and measured RL peaks is inexistent, and the experimental absorption bandwidth was $1.4 \mathrm{GHz}$. The calculated RL for the sample with $5.85 \mathrm{~mm}$ thickness ( $\mathrm{SiC} 402.85 \mathrm{~mm}+\mathrm{CB} 23.00 \mathrm{~mm}$ ) was $-20.5 \mathrm{~dB}$ at $17.8 \mathrm{GHz}$, and the measured RL was $-34.7 \mathrm{~dB}$ at $17.8 \mathrm{GHz}$. This structure had an absorption bandwidth of $1.2 \mathrm{GHz}$ in the $\mathrm{K}_{u}$-band, but it can be larger if the K-band is consider. Also, this sample presented no frequency difference between calculated and measured RL. It can be observed through these analyses that it is possible to control the absorption frequency by adjusting the thickness of the first or the second layer, allowing a frequency tuning of the structure.

(a)

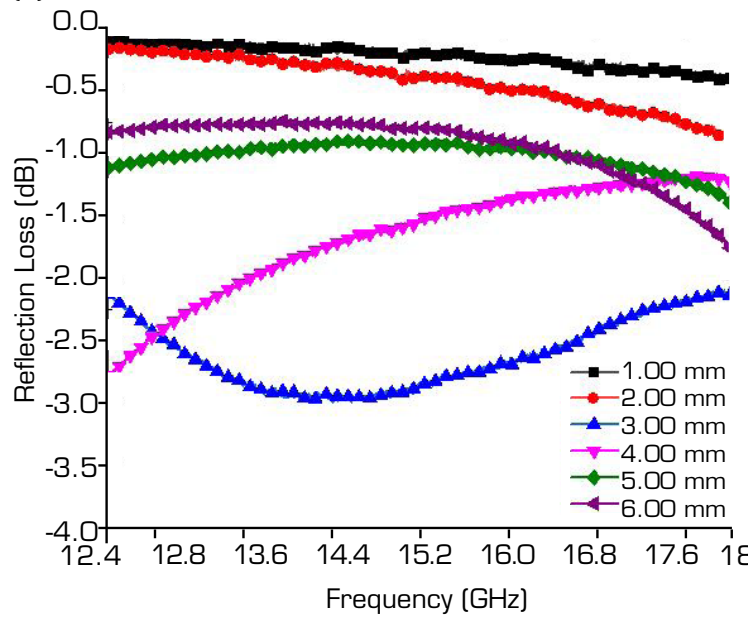

(b)

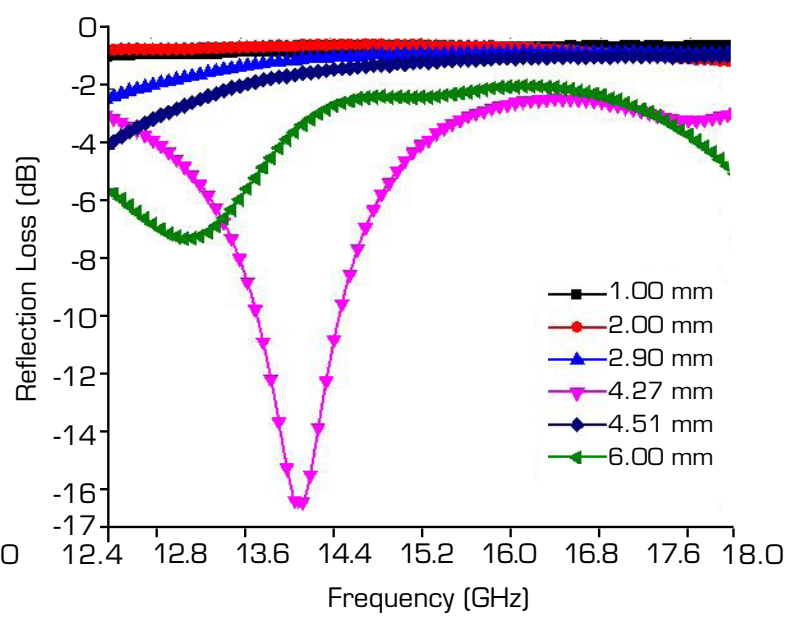

[c]

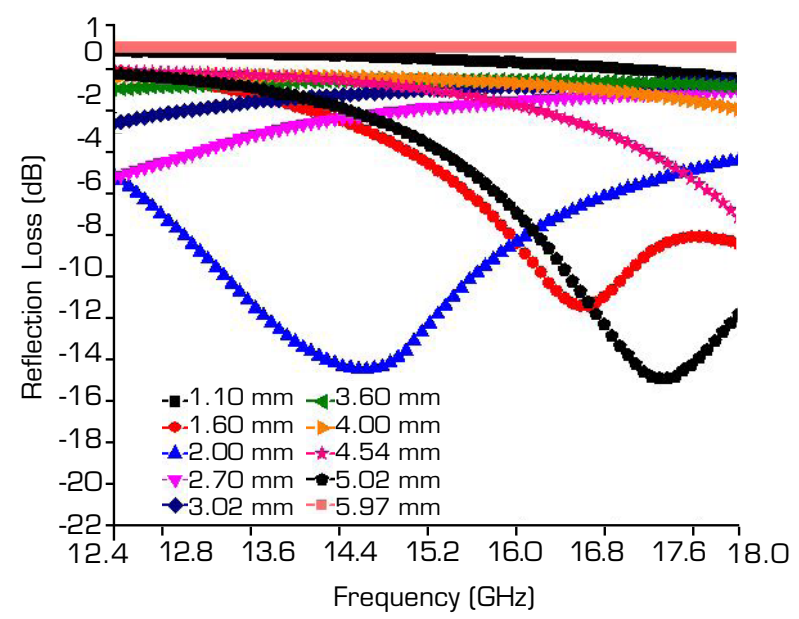

Figure 8. Reflection loss of (a) CB2 (b) MnZn60 and (c) SiC40 samples.

There is a significant improvement of the experimental RL when the results of the double layer structures are compared with the results of each single layer material. This behavior can be explained as a similar effect of a Salisbury screen (Seman et al. 2009), which is a structure consisting of an air gap between the absorber material and the metal plate. Also, the reflection loss is extremely sensitive to the structure thicknesses, and it is possible to shift the frequency of absorption by changing the thickness of the lossless layer (CB2), the thickness of the lossy layer ( $\mathrm{SiC40}$ or MnZn60), or the total thickness of the structure. Because of that, micrometric air gaps were probably responsible for the frequency mismatch between measured and calculated RL since it may have increased the total thickness of the structure in a micrometric scale. 


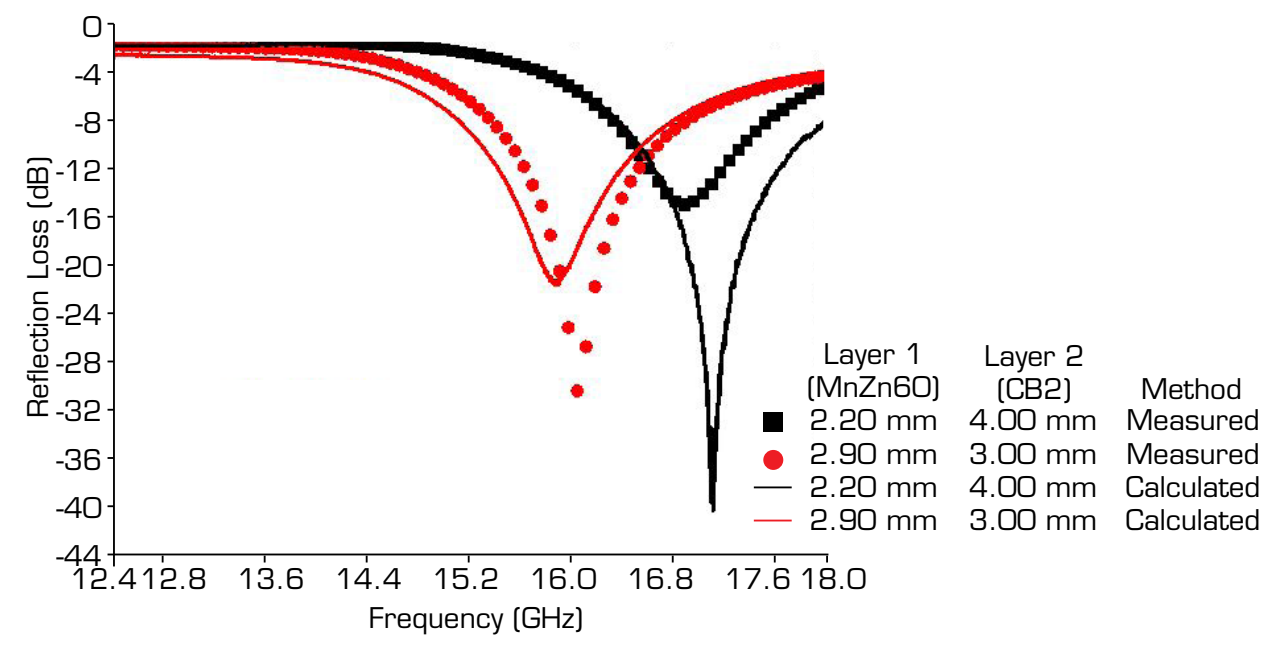

Figure 9. Calculated (line) and experimental (symbol) RL of a double layer structure with $6.20 \mathrm{~mm}$ (black) and $5.90 \mathrm{~mm}$ (red) thicknesses. The first layer is MnZn60 and the second layer is CB2.

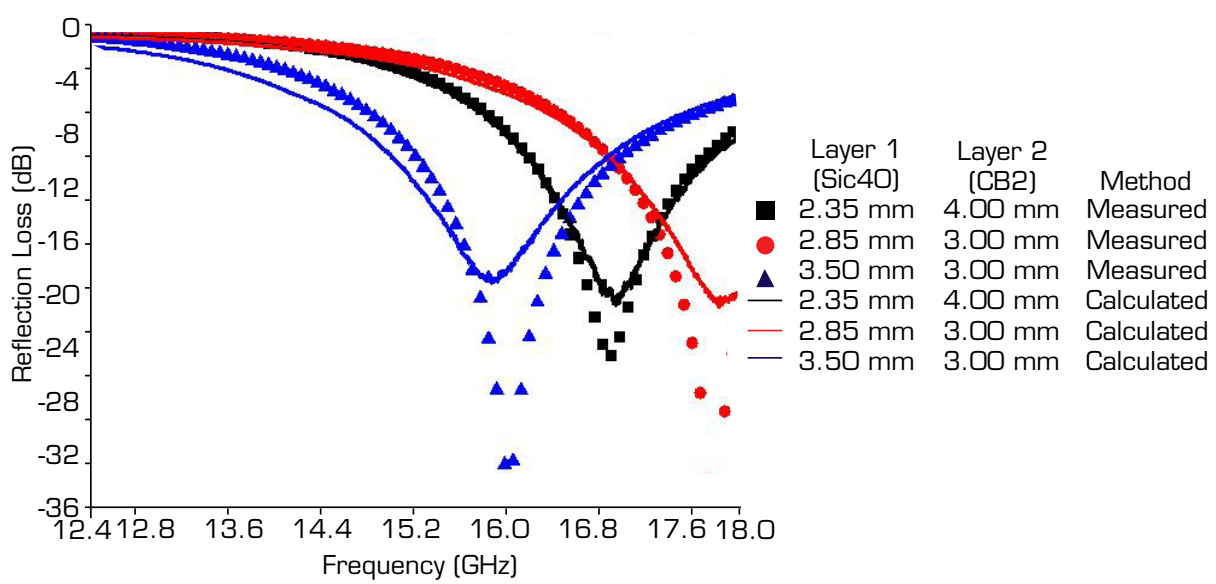

Figure 10. Calculated (line) and experimental (symbol) RL of a double layer structure with $6.35 \mathrm{~mm}$ (black), $5.85 \mathrm{~mm}$ (red) and $6.50 \mathrm{~mm}$ (blue) thicknesses. The first layer is SiC40 and the second layer is CB2.

Figure 11 presents the analysis of a double layer structure considering CB2 composite as layer 1, i.e., the layer between free space and layer 2. Considering MnZn60 composite as layer 2, the best attenuation peak appeared with the multilayer structure CB2 $4.00 \mathrm{~mm}+\mathrm{MnZn} 602.20 \mathrm{~mm}$, with total thickness of $6.20 \mathrm{~mm}$. The calculated RL reached $-11.8 \mathrm{~dB}$ at $12.9 \mathrm{GHz}$, while the measured $\mathrm{RL}$ was $-7.0 \mathrm{~dB}$ at $14.6 \mathrm{GHz}$. The frequency difference between measured and calculated $\mathrm{RL}$ is $1.7 \mathrm{GHz}$, which is higher than the previous analysis, and the RL is not significant. Now analyzing SiC40 as layer 2, the structure CB2 $4.00 \mathrm{~mm}+\mathrm{SiC} 402.35 \mathrm{~mm}$ (Fig. 8b) presented better RL, where the calculated RL was close to $-9.8 \mathrm{~dB}$ at $16.2 \mathrm{GHz}$, and the measured RL was $-16.2 \mathrm{~dB}$ at $15.6 \mathrm{GHz}$. The frequency difference between experimental and measured RL peaks is $0.6 \mathrm{GHz}$. Even with an experimental RL of $-16.2 \mathrm{~dB}$, the results are not as stunning as the double structures with CB2 as layer 2. This may be related to the number of layers in these structures. A multilayer structure with several layers can attenuate the incident wave through impedance matching, which means that each layer has a characteristic impedance close to the ones surrounding it. This allows the incident wave to penetrate better into the structure and then dissipated the energy more efficiently. 
(a)

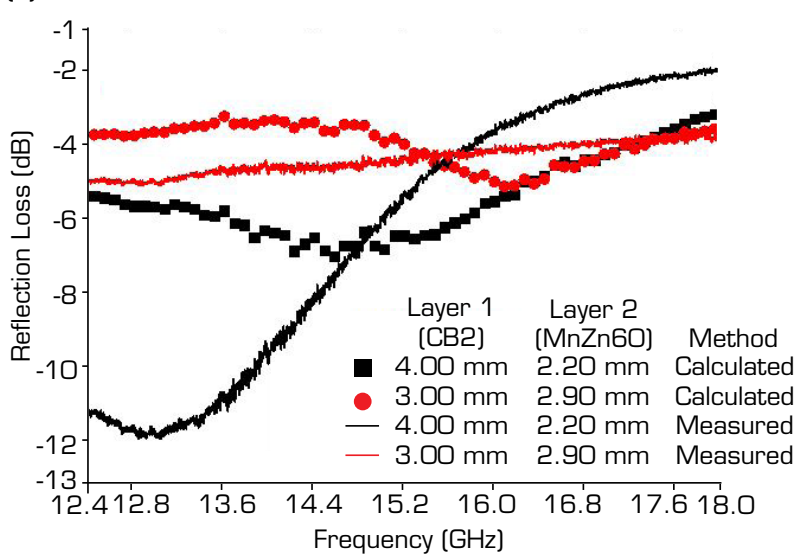

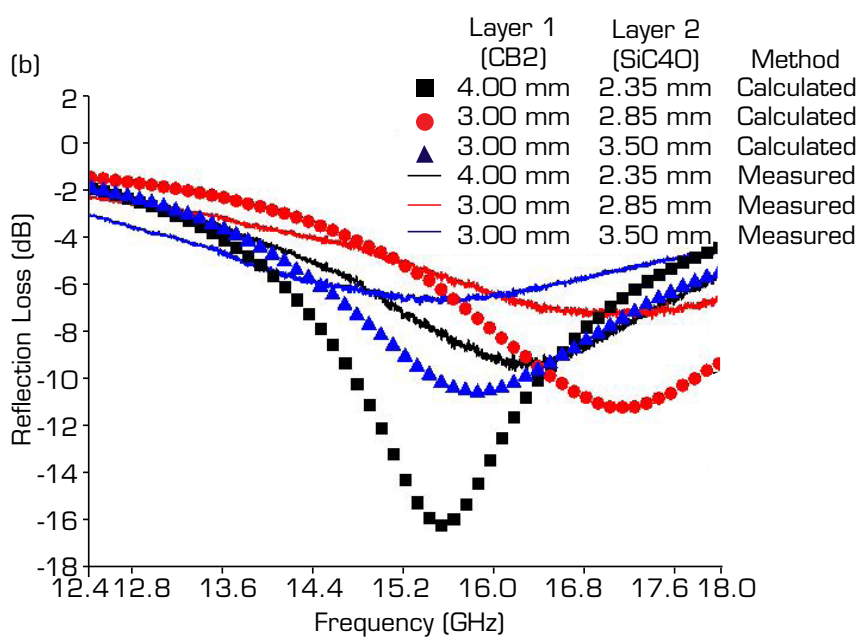

Figure 11. Reflection loss of (a) CB2 (first layer) + MnZn60 (second layer) and (b) CB2(first layer) + SiC40 (second layer) samples measured (symbol) and calculated (line).

\section{CONCLUSION}

It was demonstrated here how a multilayer structure can provide a better RL than a single layer RAM, and how it is possible to validate the calculated RL of a multilayer structure using small samples in a rectangular waveguide. For comparison, the best single layer RL result for sample $\mathrm{SiC} 40$ reached $-15.0 \mathrm{~dB}$ at $17.3 \mathrm{GHz}$, while for sample MnZn60 was close to -16.0dB at 14.1 GHz. For the multilayer structure SiC40 2.85mm + CB2 3.00mm, the experimental RL was $-34.7 \mathrm{~dB}$ at $17.8 \mathrm{GHz}$, while for the structure MnZn60 $2.90 \mathrm{~mm}$ $+\mathrm{CB} 23.00 \mathrm{~mm}$ the experimental RL was $-30.2 \mathrm{~dB}$ at $16.0 \mathrm{GHz}$. The calculated RL for these structures were $-20.5 \mathrm{~dB}$ at $17.8 \mathrm{GHz}$ and $-21.2 \mathrm{~dB}$ at $15.9 \mathrm{GHz}$, respectively. It was demonstrated that $\mathrm{CB}$ composite as layer 2 is more effective than in layer 1 . This is probably because this structure worked as a Salisbury screens, where a lossless material is between the lossy material and the metallic plate.

Also, it was demonstrated how the double layer structures can be tuned to reduce the RL in a specific frequency, simply by changing the thickness of each layer. Since the RL calculations were time-consuming because were performed in an excel spreadsheet, it is suggested as further work the implementation of an algorithm that calculates the RL of a multilayer structure with $n$ layers, using criteria like RL, total thickness and desired frequency to choose the best arrangement.

\section{AUTHOR'S CONTRIBUTION}

Conceptualization: Boss AFN; Baldan MR; Project administration: Amaral-Labat GA; Boss AFN; Baldan MR; Supervision: Boss AFN; Baldan MR; Methodology: Souza AAT; Boss AFN; Investigation: Souza AAT; Medeiros NCFL; Medeiros LI; Matheus Carvalho Bispo CM; Formal analysis: Souza AAT; Amaral-Labat GA; Visualization: Souza AAT; Validation: Souza AAT; Medeiros NCFL; Medeiros LI; Writing - original draft: Souza AAT; Boss AFN; Writing - review and editing: Souza AAT; Amaral-Labat GA; Silva GFBL; Silva GFBL; Boss AFN; Baldan MR.

\section{FUNDING}

Coordenação de Aperfeiçoamento de Pessoal de Nível Superior http://dx.doi.org/10.13039/501100002322 


\section{DATA AVAILABILITY STATEMENT}

Data will be available upon request.

\section{ACKNOWLEDGMENT}

Nila C. F. L. Medeiros and Leonardo I. Medeiros thank the support of Universidade Estadual de Santa Cruz (UESC). Gisele A. Amaral-Labat thanks the financial support of CNPq.

\section{REFERENCES}

Ahmad H, Tariq A, Shehzad A, Faheem MS, Shafiq M, Rashid IA, Afzal A, Munir A, Riaz MT, Haider HT, et al. (2019) Stealth technology: Methods and composite materials - A review. Polym Compos 40(12):4457-4472. https://doi. org/10.1002/pc.25311

Balci O, Polat EO, Kakenov N, Kocabas C (2015) Graphene-enabled electrically switchable radar-absorbing surfaces. Nat Commun 6:6628. https://doi.org/10.1038/ncomms7628

Barba AA, Lamberti G, d'Amore M, Acierno D (2006) Carbon black/silicone rubber blends as absorbing materials to reduce Electro Magnetic Interferences (EMI). Polym Bull 57(4):587-593. https://doi.org/10.1007/s00289-006-0598-Z

Calabrò E (2018) Introduction to the Special Issue “Electromagnetic Waves Pollution”. Sustainability 10(9):3326. https://doi. org/10.3390/su10093326

Cao M-S, Song W-L, Hou Z-L, Wen B, Yuan J (2010) The effects of temperature and frequency on the dielectric properties, electromagnetic interference shielding and microwave-absorption of short carbon fiber/silica composites. Carbon 48(3):788796. https://doi.org/10.1016/j.carbon.2009.10.028

Chung DDL (2004) Electrical applications of carbon materials. J Mater Sci 39(8):2645-2661. https://doi.org/10.1023/ B:JMSC.0000021439.18202.ea

Datashvili L, Baier H, Encinar JA, Legay H (2006) Mechanical investigation of a multi-layer reflectarray for $\mathrm{K}_{u}$-band space antennas. Aerosp Sci Technol 10(7):618-627. https://doi.org/10.1016/j.ast.2006.06.007

Feng YB, Qiu T, Shen CY (2007) Absorbing properties and structural design of microwave absorbers based on carbonyl iron and barium ferrite. J Magn Magn Mater 318(1-2):8-13. https://doi.org/10.1016/j.jmmm.2007.04.012

Fernández-Chimeno M, Silva F (2010) Mobile phones electromagnetic interference in medical environments: A review. Paper presented 2010 IEEE International Symposium on Electromagnetic Compatibility. IEEE; Fort Lauderdale, Florida, United States. https://doi.org/10.1109/ISEMC.2010.5711291

Gama AM, Rezende MC (2013) Complex permeability and permittivity variation of radar absorbing materials based on MnZn ferrite in microwave frequencies. Mater Res 16(5):997-1001. https://doi.org/10.1590/S1516-14392013005000077

He P, Cao M-S, Shu J-C, Cai Y-Z, Wang X-X, Zhao Q-L, Yuan J (2019) Atomic Layer Tailoring Titanium Carbide MXene to tune transport and polarization for utilization of electromagnetic energy beyond solar and chemical energy. ACS Appl Mater Interfaces 11(13):12535-12543. https://doi.org/10.1021/acsami.9b00593 
Hong W, Xiao P, Luo H, Li Z (2015) Microwave axial dielectric properties of carbon fiber. Sci Rep 5:14927. https://doi. org/10.1038/srep14927

Jani RK, Patra MK, Saini L, Shukla A, Singh CP, Vadera SR (2017) Tuning of microwave absorption properties and electromagnetic interference (EMI) shielding effectiveness of nanosize conducting black-silicone rubber composites over 8-18 GHz. Prog Electromagn Res M 58:193-204. https://doi.org/10.2528/PIERM17022704

Jayalakshmi CG, Inamdar A, Anand A, Kandasubramanian B (2019) Polymer matrix composites as broadband radar absorbing structures for stealth aircrafts. J Appl Polym Sci 136(14):47241. https://doi.org/10.1002/app.47241

Khandelwal MK, Kanaujia BK, Dwari S, Kumar S, Gautam AK (2014) Analysis and design of wide band Microstrip-linefed antenna with defected ground structure for $\mathrm{K}_{u}$ band applications. Int J Electron Commun 68(10):951-957. https://doi. $\operatorname{org} / 10.1016 /$ j.aeue.2014.04.017

Liu X, Zhang Z, Wu Y (2011) Absorption properties of carbon black/silicon carbide microwave absorbers. Compos B Eng 42(2):326-329. https://doi.org/10.1016/j.compositesb.2010.11.009

Liu Y, Luo F, Su J, Zhou W, Zhu D (2014a) Electromagnetic and microwave absorption properties of the $\mathrm{Nickel} / \mathrm{Ti}_{3} \mathrm{SiC}_{2}$ hybrid powders in X-band. J Magn Magn Mater 365:126-131. https://doi.org/10.1016/j.jmmm.2014.04.056

Liu Y, Liu X, Wang X (2014b) Double-layer microwave absorber based on $\mathrm{CoFe}_{2} \mathrm{O}_{4}$ ferrite and carbonyl iron composites. J Alloys Compd 584:249-253. https://doi.org/10.1016/j.jallcom.2013.09.049

Micheli D, Pastore R, Vricella A, Morles RB, Marchetti M (2014) Synthesys of radar absorbing materials for stealth aircraft by using nanomaterials and evolutionary computation. Paper presented 29th Congress of the International Council of the Aeronautical Sciences. ICAS; Saint Petersburg, Russia.

Nagasree PS, Ramji K, Subramanyam C, Krushnamurthy K, Haritha T (2020) Synthesis of $\mathrm{Ni}_{0.5} \mathrm{Zn}_{0.5} \mathrm{Fe}_{2} \mathrm{O}_{4}$-reinforced E-glass/ epoxy nanocomposites for radar-absorbing structures. Plast Rubber Compos 49(10):434-442. https://doi.org/10.1080/1465 8011.2020 .1793080

Oliveira APS, Rodrigues AC, Quirino SF, Vergara DEF, Pinto SS, Rezende MC, Baldan MR (2018) Study of the influence of Carbonyl iron particulate size as an electromagnetic radiation absorbing material in 12.4 to $18 \mathrm{GHz}\left(\mathrm{K}_{u}\right)$ Band. J Microw Optoelectron Electromagn Appl 17(4):619-627. https://doi.org/10.1590/2179-10742018v17i41547

Park K-Y, Han J-H, Kim J-B, Lee S-K (2011) Two-layered electromagnetic wave-absorbing E-glass/epoxy plain weave composites containing carbon nanofibers and NiFe particles. J Compos Mater 45(26):2773-2781. https://doi. org/10.1177/0021998311410467

Seman FC, Cahill R, Fusco VF (2009) Low profile Salisbury screen radar absorber with high impedance ground plane. Electron Lett 45(1):10-12. https://doi.org/10.1049/el:20093098

Vergara DEF, Lopes BHK, Quirino SF, Silva GFB, Boss AFN, Amaral-Labat GA, Baldan MR (2019) Frequency selective surface properties of microwave new absorbing porous carbon materials embedded in epoxy resin. Mat Res 22(suppl 1):e20180834. https://doi.org/10.1590/1980-5373-mr-2018-0834

Wen B, Cao M, Lu M, Cao W, Shi H, Liu J, Wang X, Jin H, Fang X, Wang W, et al. (2014) Reduced Graphene Oxides: LightWeight and High-Efficiency Electromagnetic Interference Shielding at Elevated Temperatures. Adv. Mater. 26(21):3484-3489. https://doi.org/10.1002/adma.201400108

Yadoji P, Peelamedu R, Agrawal D, Roy R (2003) Microwave sintering of Ni-Zn ferrites: comparison with conventional sintering. Mater Sci Eng B 98(3):269-278. https://doi.org/10.1016/S0921-5107(03)00063-1 
Yassuda MKH, Castro AS (2014) Influência da adição de carbeto de silício em material absorvedor de radiação eletromagnética à base de ferrita. Paper presented $21^{\circ}$ Congresso Brasileiro de Engenharia e Ciência dos Materiais. CBECIMAT; Cuiabá, Mato Grosso, Brasil.

Zang Y, Xia S, Li L, Ren G, Chen Q, Quan H, Wu Q (2015) Microwave absorption enhancement of rectangular activated carbon fibers screen composites. Compos B Eng 77:371-378. https://doi.org/10.1016/j.compositesb.2015.03.059 